\title{
Foot and Ankle Fractures at the Supination Line
}

Tim Schepers MD PhD, Esther M. van Schie - van der Weert MD, Mark R. de Vries MD PhD, Maarten van der Elst MD PhD

Department of Surgery and Traumatology, Reinier de Graaf Groep Delft,

The Netherlands

Corresponding author

T. Schepers, MD PhD

Department of Surgery and Traumatology

Reinier de Graaf Groep Delft

PO Box 5011

2600 GA Delft

The Netherlands

Tel: $+31-15-2603060$

Fax: $+31-15-2603599$ 


\section{Abstract}

Background: The supination line is a fictive line along the foot and ankle, on which over twenty fracture types and approximately ten different ligamentous sprain-injuries have been identified.

Objective: The current study was conducted to evaluate the incidence of different types of supination line injuries visible at the initial radiographs at the Emergency Department and to determine the type and percentage of misdiagnosed injuries.

Method: Retrospective study of consecutive patients who visited the Emergency Department, between January 1 and June 30, 2009, after sustaining an injury of the foot or ankle and had a radiograph taken within 24 hours of the incident.

Results: In the six-month study period 1,284 patients were included. In these cases the trauma mechanism was a sprain in 780 patients $(60.7 \%)$. Of these patients 310 suffered from a fracture (40\%). There were $36(4.6 \%)$ false-positive cases and in $91(11.7 \%)$ cases the initial diagnosis was false-negative. The number with a missed fracture expressed as a percentage of all patients with a fracture was 29.4 percent $(91 / 310)$.

Conclusion: Detection of injuries along the supination line remains difficult. This study might aid in decreasing the number of misdiagnosed injuries, which is of value as these might negatively affect outcome.

Keywords: Supination line, sprain, ankle, foot, avulsion fractures 


\section{Introduction}

Avulsion fractures of the foot or ankle occur in up to 15 percent of cases after a supination injury (1-4). These injuries occur at predetermined locations along the so called supination line. Traction injuries occur on the lateral side, whereas compression injuries can be found on the medial side. This was already described by Pouteau in 1783 and by Malgaigne in 1847 (5), but became more widely known after the publication of Hellpap in 1963 (6). However, few publications on the subject have been published since $(2,4,7,8)$.

Hellpap called the fictive line along which injuries from a sprain-trauma can be found 'the supination line' (Figure 1). More than twenty fracture types and approximately ten different ligamentous injuries have been identified along this supination line. These supination line injuries were further divided into three groups depending on traumamechanism and fracture-location (Lateral Line, Medial Line, and Transverse Line) by Dihlmann et al. (8). Table 1 shows an overview of the different sprain-injury types along the supination line reported in the literature. To date, two studies report on demographics and frequency of the various fracture types $(2,3)$ and two studies report on missed avulsion fractures in sprain injuries but do not specify per type $(8,9)$.

The current study was conducted to evaluate the incidence of different types of supination line injuries at the Emergency Department and to determine the type and percentage of injuries that were missed at first presentation. 


\section{Material and Method}

This is a retrospective study of all consecutive patients, between January 1 and June 30 , 2009, who visited the Emergency Department (ED) and had a radiograph taken within 24 hours after sustaining an injury of the foot or ankle.

Patient characteristics (i.e., age at trauma and gender), fracture characteristics (i.e., and type of fracture and affected side), and trauma mechanism (i.e., sprain injury, fall from height, falling object, stubbing, or other) were recorded from the electronic Emergency Department patient files and the picture archiving and communication system (PACS: Kodak Carestream@ 2008). In order to determine the incidence of different types of supination line injuries only the patients with a sprain injury and a radiographic abnormality included. Multiple fractures in one patient were scored individually, except in those cases where they formed a single entity such as a Lisfranc fracture dislocation or a trimalleolar ankle fracture. All digital radiographs and radiographic reports were re-evaluated by two researchers (TS, ES). Any discrepancy between reviewer and radiographic report was settled by consensus of all authors. This data was used to compare with the patient files from the ED to determine whether an injury was missed at the radiograph. 


\section{Results}

In the six-month study period 1,284 patients had one or more radiographs of their foot or ankle taken at the Emergency Department because of an acute trauma. There were 671 male $(52.3 \%)$ and 613 female (47.7\%) patients. The mean age was 30.7 years; male patients were on average 28.6 years compared with 33.1 years for female patients. The right side was injured 615 (47.9\%) times. The trauma mechanism was a sprain in 780 cases $(60.7 \%)$, 86 times a fall from height, 228 times a falling object on the foot, stubbing the foot occurred 109 times, 70 patients had a different trauma mechanism of which 33 were bicycle spoke injuries, and in 11 cases the trauma mechanism was unknown or could not be determined. In Table 2 the percentage of cases with a fracture per trauma mechanism is shown.

Table 3 shows the various fracture types occurring in patients with a sprain injury. The most frequently encountered injuries were Weber B type ankle fractures, fibular avulsion fractures, and proximal fifth metatarsal fractures. There were $36(4.6 \%)$ false-positive cases, in which the physician at the ED incorrectly treated a patient for a fracture. In 91 (11.7\%) cases the diagnosis was false-negative, in other words a fracture was missed (Table 3). The number of patients with a missed fracture expressed as a percentage of all patients with a fracture in the same location was 29.4 percent (91/310). Twenty-five $(8.1 \%)$ patients had a second injury visible at their radiographs, mainly avulsion fractures, of which 21 were not reported in the patient records. Examples of missed injuries at the supination line are shown in Figure 2, 3 and 4. 


\section{Discussion}

Sprain injuries caused 60.7 percent of all foot ankle injuries during the six-month studyperiod. Approximately 40 percent of these suffered from one or more fractures, of which twothirds were avulsion fractures indicating severe ligamentous injuries.

The most frequently encountered fractures were Weber B type ankle fractures, fibular avulsion fractures, and proximal fifth metatarsal fractures. Similar injuries types and incidence rates were identified by Fallat et al(2). The higher total amount of fractures in this study differs from that by Fallat et al. and other studies because of the inclusion of all fractures after supination injury and not only the avulsion fractures. For example, ankle fractures represented $11 \%$ of all sprain injuries in this study.

Of all 1,284 patients 11 percent of fractures had been overlooked or misdiagnosed, which is almost 30 percent when calculated as percentage of total amount of patients with a fracture. In the literature the number of missed fractures expressed as a percentage of all fractures in the same location varies between 7.6 to $18 \%$ for foot and 2.8 to $21.7 \%$ for ankle injuries (1015). Dihlmann re-examined 112 patients with a sprain-injury and found 96 (85.7\%) bony lesions, of which 60 percent was not identified at first presentation (8). Well-known foot ankle injuries with high percentages of missed fractures are anterior process fracture of the calcaneus, lateral process (snowboarders) fractures of the talus, Chopart injuries and Lisfranc fracture dislocations, which are overlooked or misdiagnosed as ankle-sprains in up to $40 \%$ of the cases in the ED (16-21). For osteochondral lesions of the talus the percentage of missed injuries might even be as high as 50\% (22). Physicians must have a high index of suspicion for these frequently overlooked injuries. Structured analysis of foot and ankle radiographs has been pointed out to aid in detecting obscure injuries (23). Using the supination line as a guideline for the structured evaluation of foot and ankle radiographs 
might be a useful tool, as many of the missed and misdiagnosed injuries, will be along this virtual line.

A potential limitation of this study might be that the precise recollection of trauma mechanism is a problem for many patients. Up to 40 to 50 percent of patients are not able to provide an adequately description on the movement of the foot at the time of injury $(1,24)$. This might explain the presence of toe fractures in this series compared to other studies.

Several different radiographic projections have been introduced to visualize possible avulsion fractures of the anterior process (25), proximal fifth metatarsal (26), distal fibula (27), talar dome (28), posterior process of the talus (29), and talar neck (30, 31). However, especially in midfoot injuries the conventional x-rays are known to lead to a large percentage of missed injuries (32), which has resulted in an increase in CT-scanning in suspected foot and ankle injuries. Obviously, this will lead to an enormous increase in the detection of small (avulsion) fractures, with unclear clinical consequences. Several studies therefore question the need for additional radiographic views (33), because of the low rate of changes in therapeutic strategies. In the current study none of the missed injuries required surgery or alteration in treatment. Although this study does not take outcome into account, it is known from the literature that missed injuries can be the source of prolonged complaints (20). On the other hand the prognostic value of avulsion fractures of the distal fibula in ankle sprains is unclear (34). Fibular avulsion fractures, as seen on conventional anteroposterior or mortise view, might negatively affect outcome in contrast to avulsion fractures seen on additional views.

In conclusion, the number of missed foot and ankle injuries remains high. Many of these injuries occur along the supination line. Detection of these, mainly avulsion, fractures is 
mandatory as they might influence outcome. The data as presented in this study may be valuable to decrease false-negative rates in the future. 


\section{References}

1. Brostrom L. Sprained ankles. 3. Clinical observations in recent ligament ruptures. Acta Chir Scand. 1965; 130: 560-9.

2. Fallat L, Grimm DJ, Saracco JA. Sprained ankle syndrome: prevalence and analysis of 639 acute injuries. J Foot Ankle Surg. 1998; 37: 280-5.

3. Van der Ent FWC. Lateral ankle ligament injury. Rotterdam: Erasmus MC; 1984.

4. Zeegers AVCM. Supination injury of the ankle joint. Utrecht: University Medical Center Utrecht; 1995.

5. Weber BG. Die Verletzungen des oberen Sprunggelenkes. Bern: Verlag Hans Huber; 1966.

6. Hellpap W. [the Neglected Lower Ankle. The "Fracture" Line of Supination.]. Arch Orthop Unfallchir. 1963; 55: 289-300.

7. Mollenhoff G, Richter J, Muhr G. [Supination trauma. A classic case]. Orthopade. 1999; 28: 469-75.

8. Dihlmann SW, Meenen NM, Bruns J. [Fracture lines of the foot]. Unfallchirurg. 1992; 95: 14851.

9. Sujitkumar P, Hadfield JM, Yates DW. Sprain or fracture? An analysis of 2000 ankle injuries. Arch Emerg Med. 1986; 3: 101-6.

10. Brandser EA, Braksiek RJ, El-Khoury GY, Saltzman CL, Marsh JL, Clark WA, et al. Missed Fractures on Emergency Room Ankle Radiographs: An Analysis of 433 Patients. Emergency Radiology. 1997; 4: 295-302.

11. Guly HR. Diagnostic errors in an accident and emergency department. Emerg Med J. 2001; 18: 263-9.

12. Pringle RG. Missed fractures. Injury. 1973; 4: 311-6.

13. Wardrope J, Chennells PM. Should all casualty radiographs be reviewed? Br Med J (Clin Res Ed). 1985; 290: 1638-40.

14. Wei CJ, Tsai WC, Tiu CM, Wu HT, Chiou HJ, Chang CY. Systematic analysis of missed extremity fractures in emergency radiology. Acta Radiol. 2006; 47: 710-7.

15. Williams SM, Connelly DJ, Wadsworth S, Wilson DJ. Radiological review of accident and emergency radiographs: a 1-year audit. Clin Radiol. 2000; 55: 861-5.

16. Funk JR, Srinivasan SC, Crandall JR. Snowboarder's talus fractures experimentally produced by eversion and dorsiflexion. Am J Sports Med. 2003; 31: 921-8.

17. Judd DB, Kim DH. Foot fractures frequently misdiagnosed as ankle sprains. Am Fam Physician. 2002; 66: 785-94.

18. Kotter A, Wieberneit J, Braun W, Ruter A. [The Chopart dislocation. A frequently underestimated injury and its sequelae. A clinical study]. Unfallchirurg. 1997; 100: 737-41.

19. Main BJ, Jowett RL. Injuries of the midtarsal joint. J Bone Joint Surg Br. 1975; 57: 89-97.

20. Schepers T, Ginai AZ, Van Lieshout EM, Patka P. Demographics of extra-articular calcaneal fractures: including a review of the literature on treatment and outcome. Arch Orthop Trauma Surg. 2008; 128: 1099-106.

21. Sherief TI, Mucci B, Greiss M. Lisfranc injury: how frequently does it get missed? And how can we improve? Injury. 2007; 38: 856-60.

22. Giza E. Operative techniques for osteochondral lesions of the talus. Foot Ankle Spec. 2008; 1: 250-2.

23. Yu JS, Cody ME. A template approach for detecting fractures in adults sustaining low-energy ankle trauma. Emerg Radiol. 2009; 16: 309-18.

24. Prins JG. Diagnosis and treatment of injury to the lateral ligament of the ankle. A comparative clinical study. Acta Chir Scand Suppl. 1978; 486: 3-149.

25. Geusens $E$, Geyskens W, Brys $P$, Janzing $H$. The role of the reversed oblique radiograph in trauma of the foot and ankle. Eur Radiol. 2000; 10: 476-9. 
26. Pao DG, Keats TE, Dussault RG. Avulsion fracture of the base of the fifth metatarsal not seen on conventional radiography of the foot: the need for an additional projection. Am J Roentgenol. 2000; 175: 549-52.

27. Haraguchi $\mathrm{N}$, Kato $\mathrm{F}$, Hayashi $\mathrm{H}$. New radiographic projections for avulsion fractures of the lateral malleolus. J Bone Joint Surg Br. 1998; 80: 684-8.

28. Thompson JP, Loomer RL. Osteochondral lesions of the talus in a sports medicine clinic. A new radiographic technique and surgical approach. Am J Sports Med. 1984; 12: 460-3.

29. Ebraheim NA, Patil V, Frisch NC, Liu X. Diagnosis of medial tubercle fractures of the talar posterior process using oblique views. Injury. 2007; 38: 1313-7.

30. Miyamoto $\mathrm{W}$, Takao $\mathrm{M}$, Nishiguchi $\mathrm{K}$, Uchio $\mathrm{Y}$. Technique tip: a radiographic projection for an avulsion fracture of the talar attachment of the anterior talofibular ligament. Foot Ankle Int. 2008; 29: 435-7.

31. Canale ST, Kelly FB, Jr. Fractures of the neck of the talus. Long-term evaluation of seventyone cases. J Bone Joint Surg Am. 1978; 60: 143-56.

32. Haapamaki VV, Kiuru MJ, Koskinen SK. Multidetector CT in shoulder fractures. Emerg Radiol. 2004; 11: 89-94.

33. Noh JH, Yang BG, Yi SR, Lee SH, Song $\mathrm{CH}$. Outcome of the functional treatment of first-time ankle inversion injury. J Orthop Sci. 2010; 15: 524-30.

34. Haraguchi N, Toga H, Shiba N, Kato F. Avulsion fracture of the lateral ankle ligament complex in severe inversion injury: incidence and clinical outcome. Am J Sports Med. 2007; 35: 1144-52.

\section{Conflict of Interest statement}

No conflict of interest for any of the authors 
Table 1. Literature overview of injuries marked as 'supination line injury'

\begin{tabular}{|c|c|c|c|c|c|}
\hline $\begin{array}{l}\text { Supination line injuries } \\
\text { (distal to proximal) }\end{array}$ & 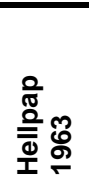 & 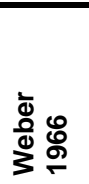 & 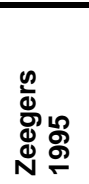 & 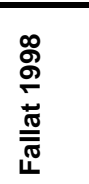 & 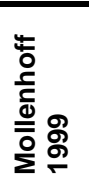 \\
\hline Fifth metatarsal shaft fracture & $\mathrm{x}$ & $\mathrm{X}$ & $\mathrm{X}$ & & \\
\hline Fifth metatarsal proximal fracture & $\mathrm{x}$ & $\mathrm{x}$ & $\mathrm{x}$ & $\mathrm{x}$ & $\mathrm{x}$ \\
\hline Lisfranc injury & & & & $\mathrm{x}$ & \\
\hline Cuboid (avulsion) fracture & $\mathrm{x}$ & & $x$ & $\mathrm{x}$ & $x$ \\
\hline Calcaneocuboid ligament injury & & $\mathrm{x}$ & & & $x$ \\
\hline Navicular (avulsion) fracture & & $x$ & $x$ & $x$ & $x$ \\
\hline Sustentaculum tali fracture & & & & & $x$ \\
\hline Lateral calcaneal avulsion & $\mathrm{x}$ & & & $\mathrm{x}$ & \\
\hline Anterior process calcaneus & $x$ & $x$ & $\mathrm{x}$ & $\mathrm{x}$ & $x$ \\
\hline \multicolumn{6}{|l|}{ Ext digitorum brevis avulsion } \\
\hline Calcaneus tuber avulsion & & & & & $x$ \\
\hline Talar body fracture & & $x$ & $\mathrm{x}$ & $\mathrm{x}$ & $x$ \\
\hline Osteochondral lesion talus & & & & $\mathrm{x}$ & \\
\hline Lateral process talus & & & $\mathrm{x}$ & $\mathrm{x}$ & $x$ \\
\hline Posterior process talus & & & & $x$ & $x$ \\
\hline Dorsal talar neck avulsion & & & & $x$ & $x$ \\
\hline Medial talar avulsion & & & & $x$ & \\
\hline Lateral malleolus (avulsion) & & & $x$ & $\mathrm{x}$ & $x$ \\
\hline Medial malleolus (avulsion) & & & & $\mathrm{x}$ & \\
\hline Posterior malleolus & & & & & $\mathrm{x}$ \\
\hline
\end{tabular}


Table 2. Number of patients with a fracture per trauma mechanism

\begin{tabular}{lccc}
\hline Trauma mechanism & Patients (N) & $\begin{array}{l}\text { Cases with } \\
\text { fracture (N) }\end{array}$ & Fracture rate (\%) \\
\hline Sprain (See table 3) & 780 & 310 & 40 \\
Fall from height & 86 & 37 & 43 \\
Object on foot & 228 & 62 & 27 \\
Stubbing & 109 & 53 & 49 \\
Rest & 70 & 14 & 20 \\
Unknown & 11 & 2 & 18 \\
Total & 1,284 & 478 & 37 \\
\hline
\end{tabular}

This table represents all patients during the six month study-period who had a radiograph taken at the ED for a foot and/or ankle injury. The sprain injuries are specified in Table 3. 
Table 3. Fracture types encountered in patients with a sprain injury

\begin{tabular}{|c|c|c|c|}
\hline Fracture type & Total (N) & $\begin{array}{l}\text { Percentage } \\
\text { of all sprain } \\
\text { cases }\end{array}$ & $\begin{array}{l}\text { Percentage } \\
\text { missed } \\
\text { fractures }\end{array}$ \\
\hline Weber B & 61 & 7.8 & 1.6 \\
\hline Lateral malleolus avulsion & 45 & 5.8 & 40 \\
\hline MT5 proximal/avulsion & 32 & 4.1 & 25 \\
\hline Anterior process calcaneus & 17 & 2.2 & 88.2 \\
\hline Navicular body or avulsion & 16 & 2.1 & 68.9 \\
\hline Weber C & 15 & 1.9 & 0 \\
\hline Dorsal talar neck avulsion & 11 & 1.4 & 63.6 \\
\hline Medial malleolus avulsion & 11 & 1.4 & 63.6 \\
\hline Cuboid body or avulsion & 11 & 1.4 & 72.7 \\
\hline Weber A & 10 & 1.3 & 10 \\
\hline Toe fractures & 9 & 1.2 & 33.3 \\
\hline MT1,2,3,or 4 & 8 & 1.0 & 0 \\
\hline Multiple MT & 8 & 1.0 & 0 \\
\hline Lateral (process) talus avulsion & 7 & 0.9 & 42.9 \\
\hline MT5 Jones & 7 & 0.9 & 42.9 \\
\hline MT5 distal & 6 & 0.8 & 33.3 \\
\hline Osteochondral lesion talus & 6 & 0.8 & 66.7 \\
\hline Lisfranc fracture-dislocation & 6 & 0.8 & 0 * \\
\hline Medial mallolus & 5 & 0.6 & 0 \\
\hline Distal tibia & 5 & 0.6 & 0 \\
\hline SH-2 lat malleolus & 4 & .5 & 50 \\
\hline Ext dig brevis avulsion & 4 & 0.5 & 100 \\
\hline Distal crural & 4 & 0.5 & 0 \\
\hline Cuneiform complete or avulsion & 4 & 0.5 & 75 \\
\hline Medial talar avulsion & 4 & 0.5 & 75 \\
\hline SH-1 lat malleolus & 3 & 0.4 & 33.3 \\
\hline Calcaneal tuber avulsion & 3 & 0.4 & 0 \\
\hline MT5 shaft & 3 & 0.4 & 0 \\
\hline
\end{tabular}




\begin{tabular}{llll}
\hline Posterior malleolus & 2 & 0.3 & 0 \\
Calcaneocuboid ligament injury & 2 & 0.3 & 100 \\
Calcaneal & 2 & 0.3 & 0 \\
Lateral process calcaneus & 1 & 0.1 & 100 \\
Sustentaculum tali & 1 & 0.1 & 100 \\
Chopart fracture-dislocation & 1 & 0.1 & 0 \\
\hline
\end{tabular}

The various fracture types are ranked from highest to lowest rate of occurrence

MT, metatarsal; SH. Salter-Harris classification type

*. Injuries were detected in all, but not labelled as a Lisfranc fracture-dislocation in $75 \%$ 
Figure 1. A graphical representation of the supination line

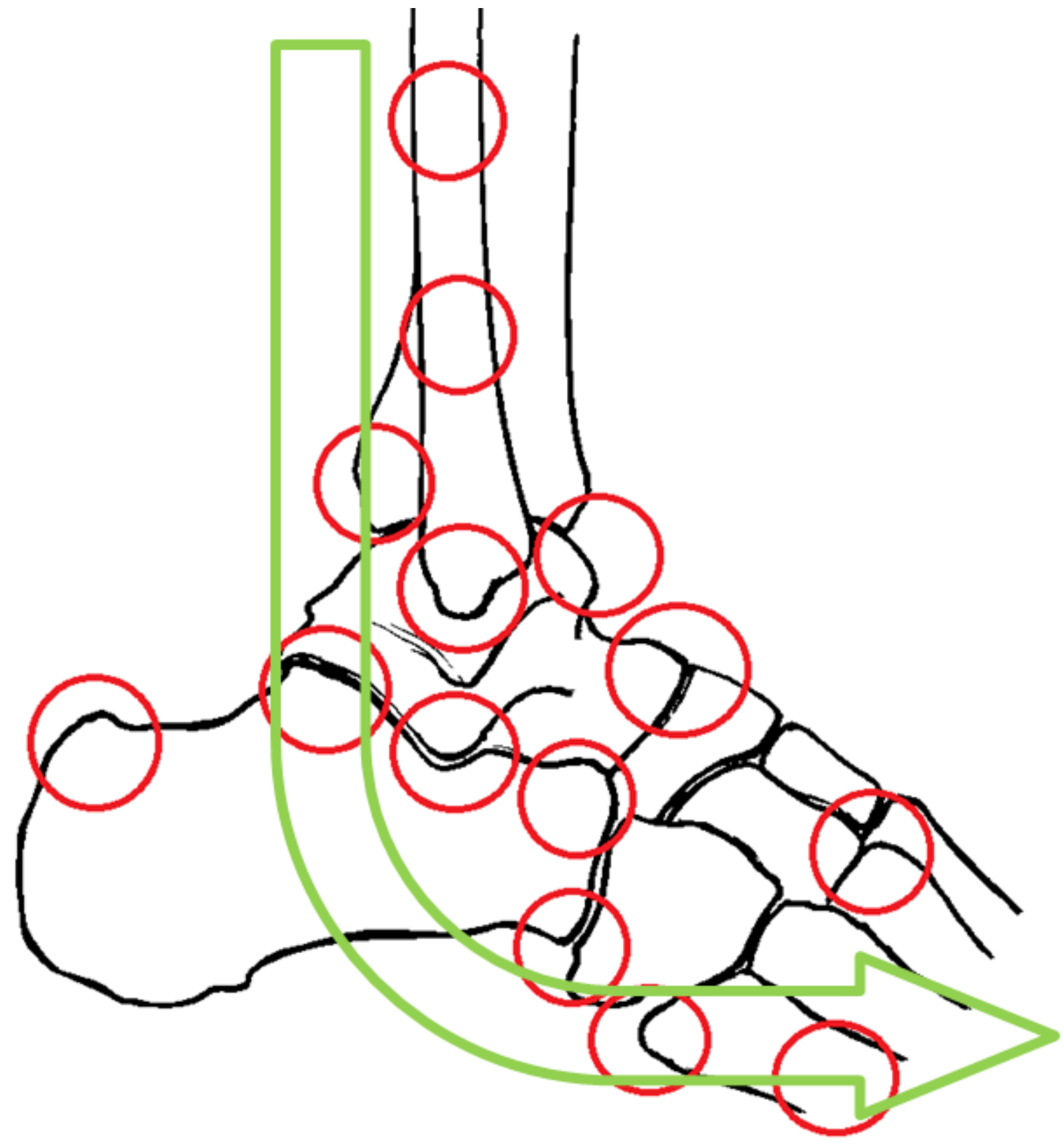

The Supination line (Green arrow) is a fictive line along which various sprain-injuries (Red circles) can occur. 
Figure 2. Misdiagnosed calcaneal injuries at the supination line
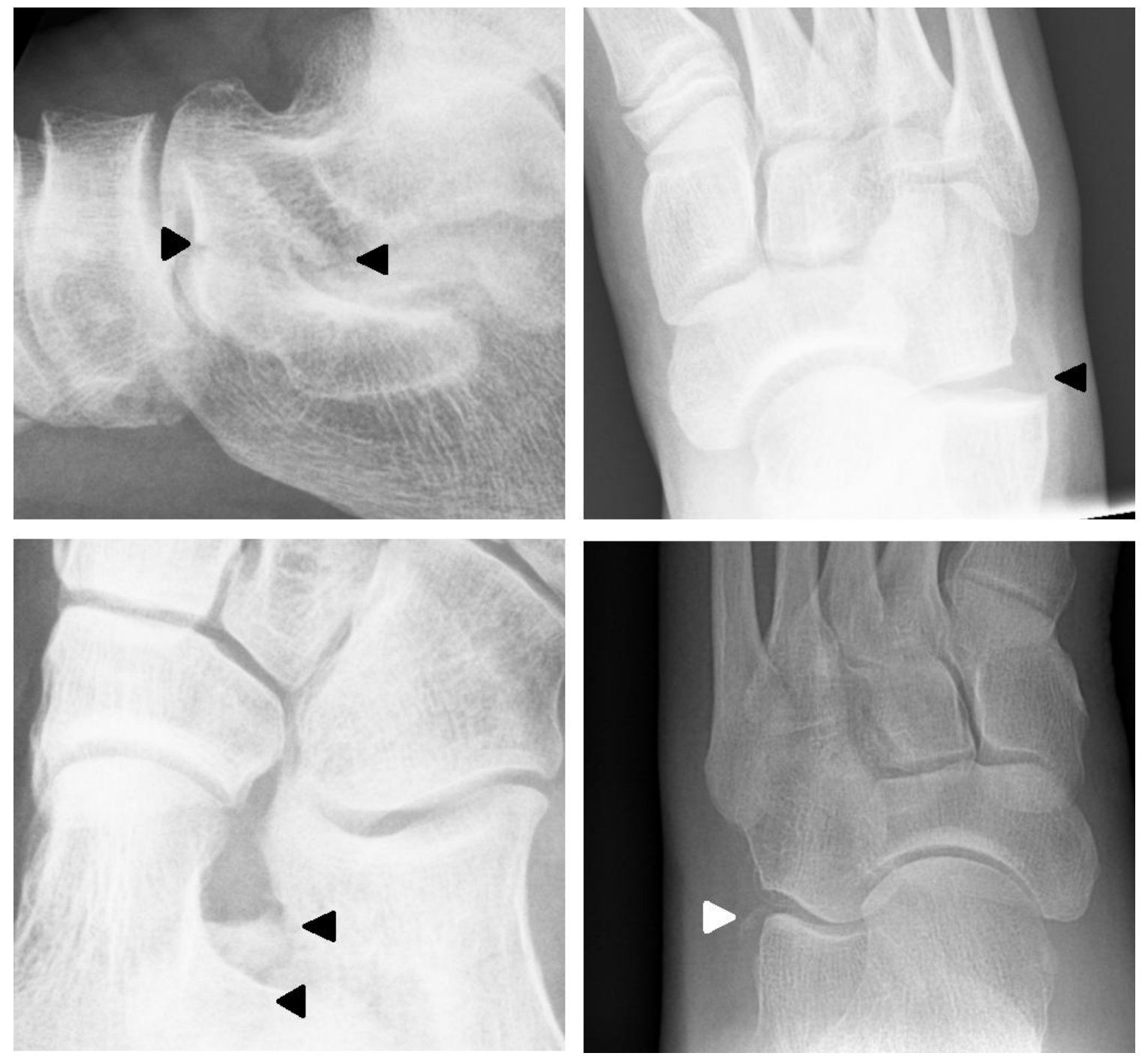

a, anterior process fracture calcaneus; b, calcaneocuboid ligamentous injury; c, sustentaculum tali fracture; $d$, anterior process fracture calcaneus 
Figure 3. Misdiagnosed midfoot injuries at the supination line
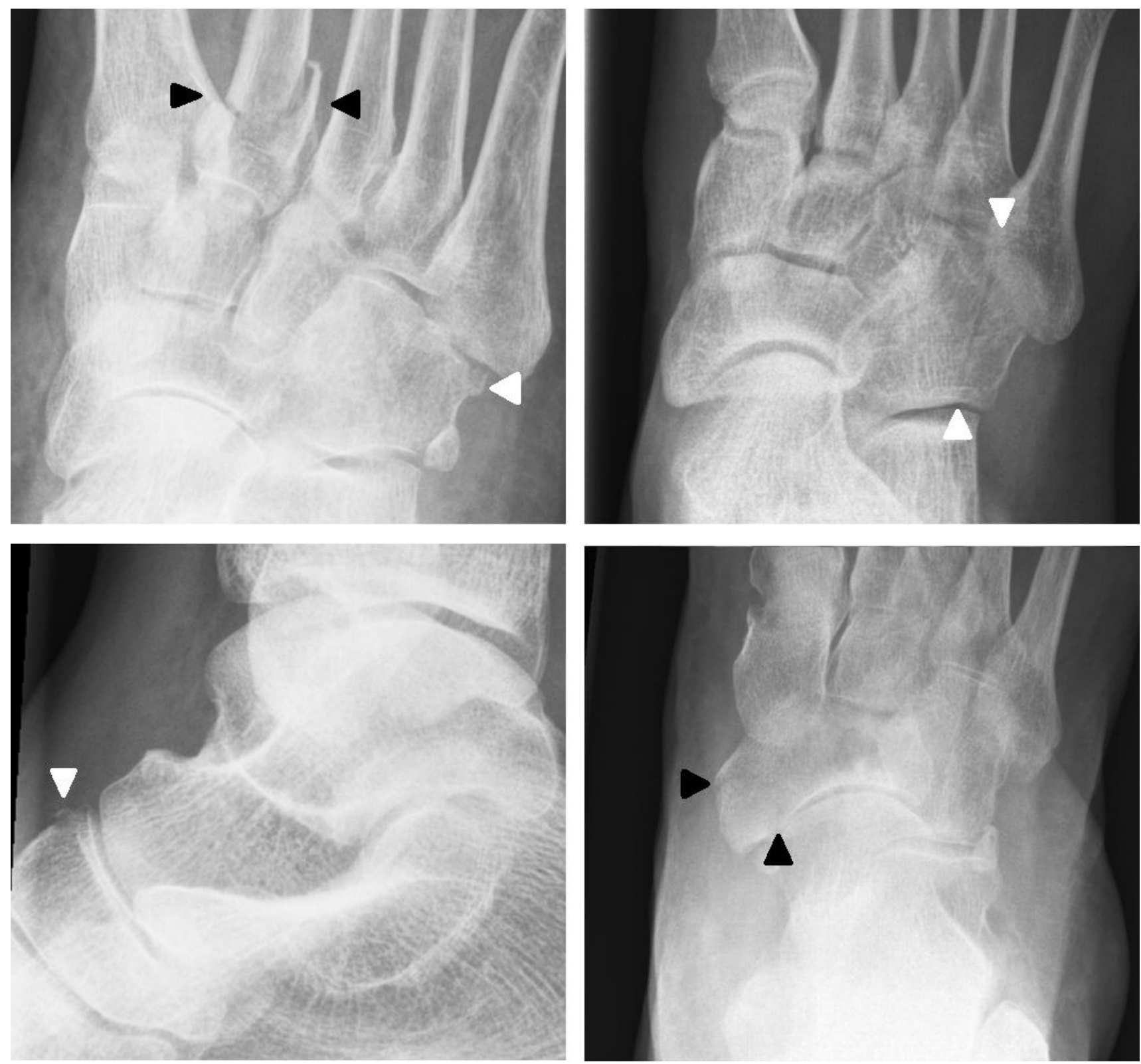

a, the fracture at the second metatarsal was noted, however the cuboid fracture, indicating a Lisfranc injury, was missed; b, cuboid body fracture; c, navicular avulsion fracture; d, navicular fracture 
Figure 4. Misdiagnosed talar injuries at the supination line
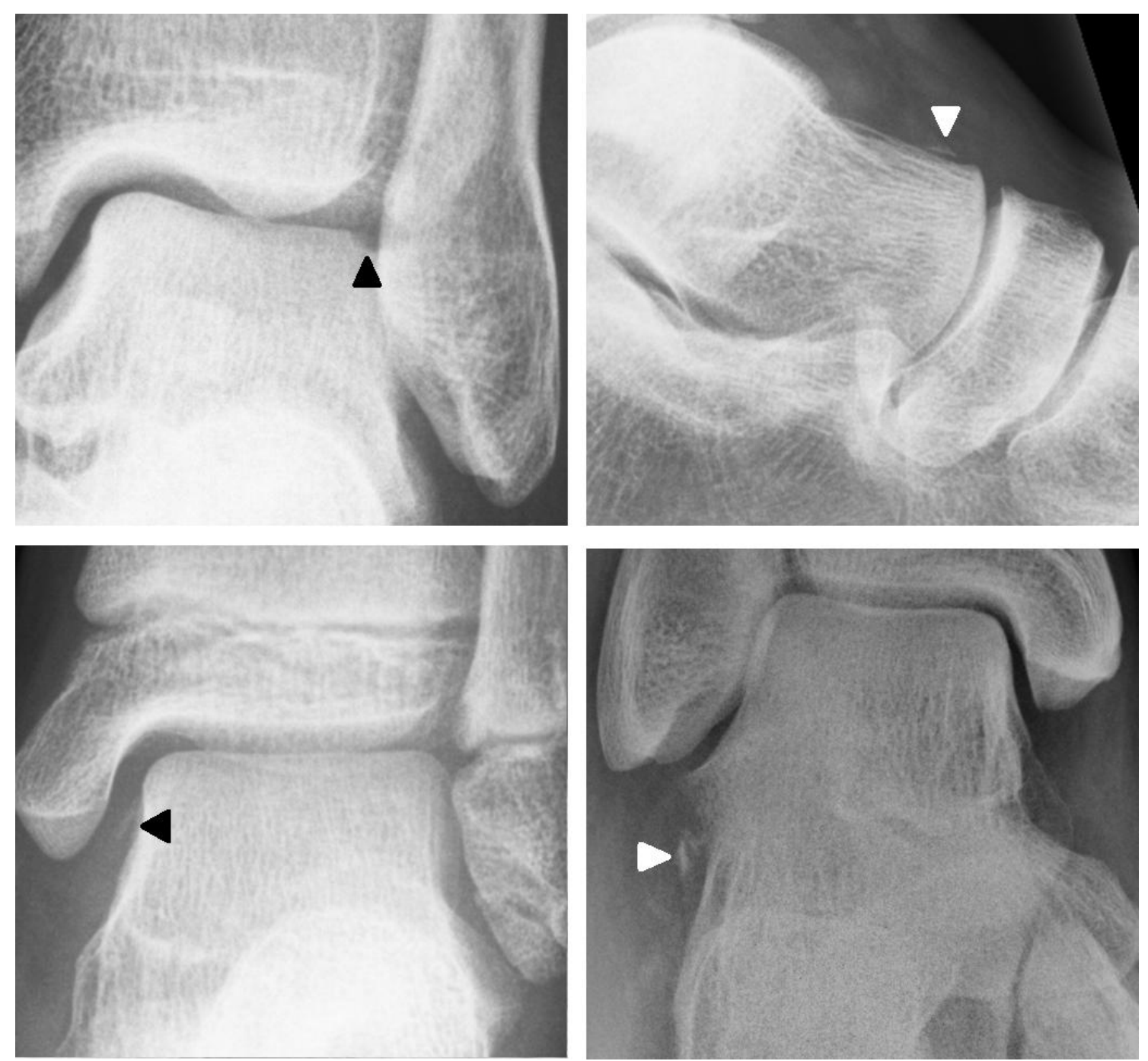

a, osteochondral lesion talus; b, talar head avulsion fracture; c, osteochondral lesion talus; $d$, lateral process fracture talus 